\title{
pharmaceuticals
}

ISSN 1424-8247

Article

www.mdpi.com/journal/pharmaceuticals

\section{Cell-Penetrating Peptides: A Comparative Study on Lipid Affinity and Cargo Delivery Properties}

\author{
Paolo Ruzza *, Barbara Biondi, Anna Marchiani, Nicola Antolini and Andrea Calderan \\ Institute of Biomolecular Chemistry of CNR, Padova Unit, and Department of Chemical Sciences, \\ University of Padova, via Marzolo 1, I-35131 Padova, Italy \\ * Author to whom correspondence should be addressed; E-Mail: paolo.ruzza@unipd.it; Tel.: +39- \\ 049-827-5282; Fax: +39-049-827-5239.
}

Received: 22 December 2009; in revised form: 23 March 2010 / Accepted: 29 March 2010 /

Published: 30 March 2010

\begin{abstract}
A growing number of natural and/or synthetic peptides with cell membrane penetrating capability have been identified and described in the past years. These molecules have been considered promising tools for delivering bioactive compounds into various cell types. Although the mechanism of uptake is still unclear, it is reasonable to assume that the relative contribute of each proposed mechanism could differ for the same peptide, depending on experimental protocol and cargo molecule composition. In this work we try to connect the capability to interact with model lipid membrane and structural and chemical characteristics of CPPs in order to obtain a biophysical classification that predicts the behavior of CPP-cargo molecules in cell systems. Indeed, the binding with cell membrane is one of the primary step in the interaction of CPPs with cells, and consequently the studies on model membrane could become important for understanding peptide-membrane interaction on a molecular level, explaining how CPPs may translocate a membrane without destroying it and how this interactions come into play in shuttling CPPs via different routes with different efficiency. We analyzed by CD and fluorescence spectroscopies the binding properties of six different CPPs (kFGF, Nle ${ }^{54}$-Antp and Tat derived peptides, and oligoarginine peptides containing 6,8 or 10 residues) in absence or presence of the same cargo peptide (the 392-401p $\mathrm{Tyr}^{396}$ fragment of HS1 protein). The phospholipid binding properties were correlated to the conformational and chemical characteristics of peptides, as well as to the cell penetrating properties of the CPP-cargo conjugates. Results show that even if certain physico-chemical properties (conformation, positive charge) govern CPP capability to interact with the model membrane, these cannot fully explain cell-permeability properties.
\end{abstract}


Keywords: antennapedia; kFGF; Tat; poly-arginine peptides; conformational studies; lipid affinity

Abbreviations: DIEA, $N, N$-diisopropylethylamine; DMF, $N, N$-dimethylformamide; DMPC, 1,2-dimyristoyl-rac-glycero-3-phosphocholine; DMPG, 1,2-dimyristoyl-snglycero-3-phospho-rac-(1-glycerol); EDTA, ethylenediaminetetraacetic acid; Fmoc, 9Hfluoren-9-ylmethoxycarbonyl; HBTU, O-(benzotriazol-1-yl)- $N, N, N^{\prime}, N^{\prime}$-tetramethyluronium hexafluorophosphate; HOBt, 1-Hydroxybenzotriazole; SDS, sodium dodecyl sulfate; TFA, trifluoroacetic acid; TFE, 2,2,2-trifluoroethanol; TIS, triisopropylsilane; Tris, tris(hydroxymethyl) aminomethane.

\section{Introduction}

The process of introducing biological active molecules into cells, to interact with intracellular targets, has proved a major challenge for researchers and the pharmaceutical industry. The inability of peptides and oligonucleotides to cross membranes has been one of the principal obstacles to their use as tools to study cellular processes and in the development of drug candidates [1,2]. Over the last two decades a growing number of natural or synthetic peptides have been discovered with cell membrane penetranting capability and considered as promising tools for delivering bioactive compounds, which are poorly internalized by themselves, into various cell types (an exhaustive discussion can be found in [3]).

Several of these cell-penetrating peptides (CPPs) correspond to protein fragments representing either the basic region derived from the corresponding RNA-/DNA-binding domain or the hydrophobic core (h-region) of the signal sequence region. This last CPP is represented by the peptide corresponding to the sequence 7-22 of the fibroblast growth factor of the Kaposi's sarcoma, named kFGF [4-6].

The HIV-1 Tat peptide sequence is an example of a CPP originated from protein basic regions. Originally the full length protein evidenced the ability to cross plasma membrane and subsequently small fragments, which efficiently enter cells, have been discovered. Through mutagenesis studies it was found that Tat penetrating capability resides in the fragment 48-60 [7,8].

Another basic peptide is represented by the third helix of the homeodomain of the Antennapedia transcription factor. The internalization property of this domain was established during studies on the neural development of Drosophila in 1991, in particular the region comprising residues 43-58, corresponding to the third helix, has been identified as responsible of penetration capability $[9,10]$.

Additional CPPs, such as oligoarginines, have been designed, based on studies recognizing the importance of positively charged residues, and in particular of the guanido group, to mediate transport across cell membrane [11]. Indeed, although CPPs show a highly variable structure, some general features, as an abundance of positive charges, especially from arginine residues, and the presence of bulky side-chain hydrophobic amino acids, have been suggested to be essential for an efficient cellular uptake [12]. 
Despite a general acceptance of these molecules as vectors, the mechanism of cellular internalization and membrane permeation is still in debate. Various uptake mechanisms seem to be active in different systems and sometimes the mechanism results to be dependent on cell-type or cargo. Two major routes govern the access of CPPs to cell: endocytosis, an energy dependent vesicular mechanism, in which extracellular molecules are incorporated in lipid vesicles which are internalized; and a second route which proceed through direct translocation, in this case CPPs cross the membrane bilayer in an energy-independent process [2]. The most shared hypothesis proposes that translocation occurs via endocytosis or macropinocytosis followed by partial escape from the endocytotic vesicles of lysosomes. It is now clear that the uptake of Tat and oligoarginine, as well as that of SynB5 and Antp, proceeds mainly by an endocytic pathway rather than temperature-independent translocation [13]. On the other hand, the uptake of Tat and oligoarginines under endocytosis-blocking conditions was demonstrated recently [13], suggesting that cell-penetrating peptides are internalized by more than one mechanism, sometimes even in parallel. It is thus reasonable to assume that the relative contribution of each mechanism could differ, depending on the experimental protocol and on the nature of cargo molecules. It is possible that the ability to disturb the membrane, or the capability to bind to and thereby recruit specific membrane components, is an important event to start up the endocytotic machinery. Consequently, the studies of CPPs in model membrane could become fundamental for understanding peptide-membrane interaction on a molecular level, explaining how CPPs may translocate a membrane without destroying it and how peptide-membrane interactions come into play in shuttling CPPs via different routes with different efficiency.

Table 1. Names and sequences of the investigated peptides.

\begin{tabular}{|c|c|c|}
\hline Nr. & Peptide & Sequence \\
\hline 1 & KFGF & ${ }^{7}$ AAVALLPAVLLALLAP ${ }^{22}$ \\
\hline 1a & kFGF-HS1pY & AAVALLPAVLLALLAPPEGDPYEEVLE \\
\hline 2 & Nle $^{54}$-Antp & ${ }^{43}$ RQIKIWFQNRR-Nle-KWKK ${ }^{58}$ \\
\hline $2 a$ & Nle $^{54}$-Antp-HS1pY & RQIKIWFQNRR-Nle-KWKKPEGDpYEEVLE \\
\hline 3 & Tat & ${ }^{48}$ GRKKRRQRRRPPQG ${ }^{61}$ \\
\hline 3a & Tat-HS1pY & GRKKRRQRRRPPQGPEGDpYEEVLE \\
\hline 4 & R6 & RRRRRR \\
\hline 4a & R6-HS1pY & RRRRRRPEGDPYEEVLE \\
\hline 5 & $\mathbf{R 8}$ & RRRRRRRR \\
\hline $5 a$ & R8-HS1pY & RRRRRRRRPEGDpYEEVLE \\
\hline 6 & R10 & RRRRRRRRRR \\
\hline \multirow[t]{2}{*}{$6 \mathbf{a}$} & R10-HS1pY & RRRRRRRRRRPEGDPYEEVLE \\
\hline & HS1pY & ${ }^{392} P E G D p Y E E V L E^{401}$ \\
\hline
\end{tabular}

The aim of these studies is settled to clarify the structure-activity relationship for the interaction of peptides with membranes, try to identify the role of conformation on the interaction with lipid bilayers and the effect of cargo on it, besides the influence of lipid composition on peptide-lipid interactions 
and translocation [14] in order to obtain a biophysical classification that could predict the behavior in cell systems. Using both fluorescence and circular dichroism (CD) spectroscopies we studied the interaction and the conformation of different CPPs (Table 1) and their constructs with a phosphotyrosine containing peptide derived from the hematopoietic lineage cell-specific protein 1 (HS1) protein [15], with small unilamellar vesicles (SUVs) of different charge density.

\section{Results and Discussion}

In the overwhelming body of literature on peptides or proteins able to cross biological membranes and to promote the delivery of drugs into cells, few studies have been reported in which different vectors have been applied to the same delivery problem and, in particular, on the correlation between conformation and internalization properties. In this paper, we estimated the ability of different CPPs to interact with simplified model membranes to obtain information, on a molecular level, on CPP-lipid interactions by complementary methods based on the fluorescent properties of carboxyfluoresceinyllabeled derivatives and on the chiroptical properties of peptides. The variables addressed in this study comprise charge and composition of the membrane-mimicking environment in addition to the vector composition. In particular, to investigate the specificity of peptides towards lipid vesicles, depending on lipid head groups, anionic and zwitterionic lipids were used.

The ability of $\mathrm{kFGF}$, modified $\mathrm{Nle}^{54}$-Antp, Tat, and oligoarginine peptides to deliver into cell has been demonstrated by different authors [4-11]. However, the application of these CPPs to the same cargo and its influence on lipid-interactions has not been completely elucidated. In this work, we used as cargo the phosphopeptide, corresponding to the sequence $392-401 \mathrm{pTyr}^{396}$ of the HS1 protein (HS1pY), which previously we demonstrated to be a potent inhibitor of the secondary HS1 phosphorylation, acting at level of the Src-homology 2 domains (SH2) mediate protein recruitment $[10,14]$.

\subsection{Peptide binding to phospholipid}

The affinity of CPPs, alone and conjugated to HS1pY, towards phospholipid vesicles was assessed by titration of carboxyfluoresceinyl-labeled peptide solutions with liposomes of different composition (an example of titration is reported in Figure 1). As shown in Figure 1, carboxyfluorescein emission is sensitive to environment change, showing a quenching when labeled peptides are in a more hydrophobic environment after addition of phospholipids [16]. The fluorescence quenching was used to generate the binding isotherm of the labeled peptides and then to calculate the related partition coefficient $\left(\mathrm{K}_{\mathrm{p}}\right)$. 
Figure 1. Quenching of carboxyfluorescein fluorescence emission in peptide 6a by DMPG SUVs $(15.0 \mathrm{mM})$ titration. Excitation wavelength $485 \mathrm{~nm}$. Peptide $0.3 \mu \mathrm{M}$ in $5 \mathrm{mM}$ Tris$\mathrm{HCl}$ buffer, $\mathrm{pH}$ 6.8. Phospholipid/peptide molar ratio ranging from 0.00 to 1.57 .

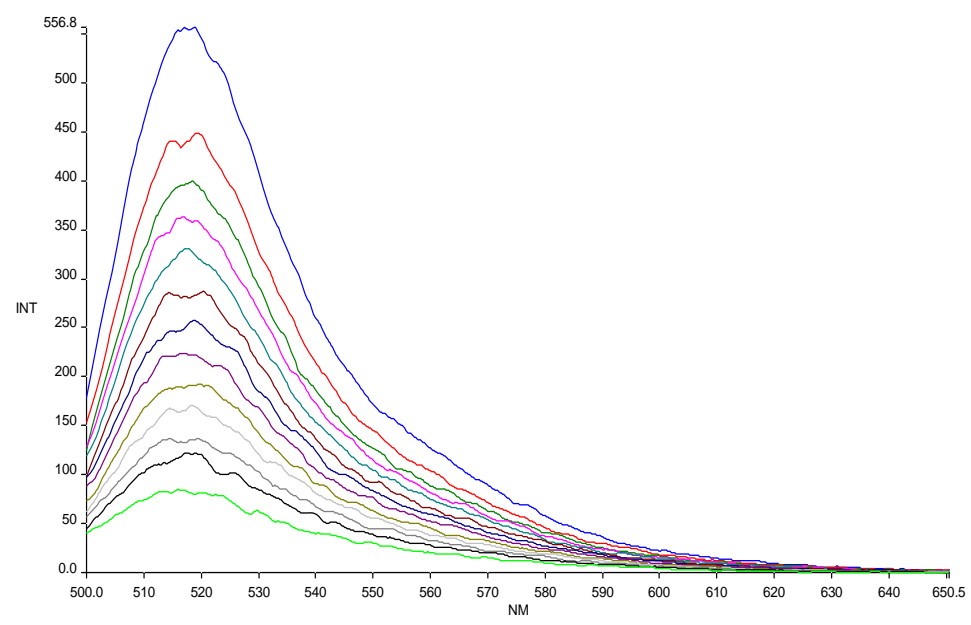

Conventional binding curves were obtained by plotting the $\Delta \mathrm{F} / \Delta \mathrm{F}_{\infty}$ as a function of lipid-to-peptide molar ratio (Figure 2A). Assuming that the peptides were initially portioned only over the outer leaflet of SUVs, conventional binding isotherm (Figure 2B) was constructed plotting the correct molar ratio of bound peptide per $60 \%$ of the total lipid $\left(\mathrm{X}_{\mathrm{b}}{ }^{*}\right)$ vs. the equilibrium concentration of free peptide in the solution $\left(\mathrm{C}_{\mathrm{f}}\right)$. The surface partition coefficients $\mathrm{K}_{\mathrm{p}}$ are estimated by extrapolating the initial slopes of the curves to zero $C_{f}$ values and the resulted values are summarized in Table 2 and in Figure 3.

Figure 2. Saturation (A) and binding isotherm (B) curves of peptide 6a $(0.3 \mu \mathrm{M})$ titrated by DMPG SUVs $(15.0 \mathrm{mM})$ in $5 \mathrm{mM}$ Tris- $\mathrm{HCl}$ buffer, $\mathrm{pH}$ 6.8. Calculated $\mathrm{K}_{\mathrm{p}}$ is $1.5 \times 10^{9}$, with an $\mathrm{R}$ value of 0.995 for the linear fit. Reported values represent means of three separate experiments.

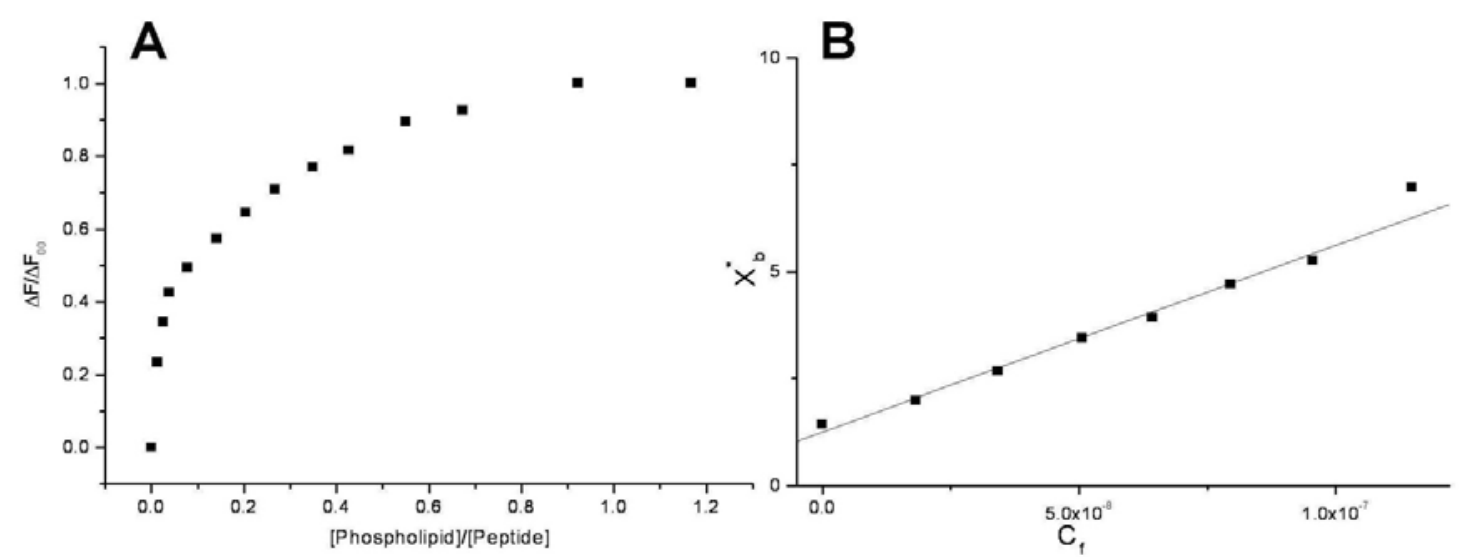


Figure 3. Comparison between the logarithmic values of the surface partition coefficients $\left(\mathrm{pK}_{\mathrm{p}}\right)$ of CPPs and corresponding conjugated peptides. CPPs are represented by open symbols, meanwhile CPP-HS1pY peptides are represented by solid symbols.

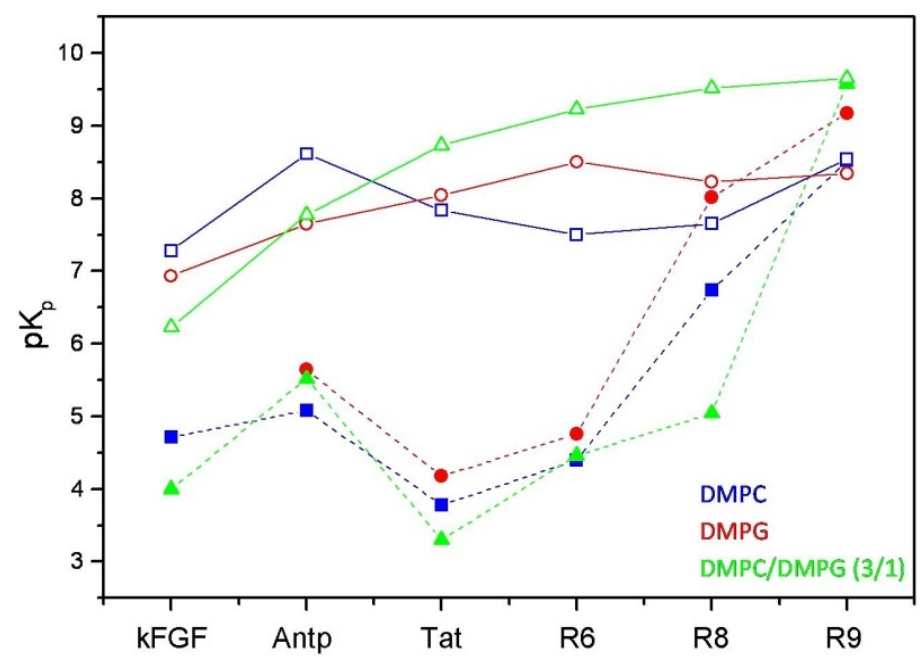

The calculated values (Table 2) confirm the strong dependence of the peptide-lipid interactions on the nature and composition of both vesicles and peptides. As shown in Figure 3, reporting the logarithmic values of $\mathrm{K}_{\mathrm{p}}$ of respective peptides, a first distinctive feature of un-conjugated CPPs is their different selectivity towards neutral (zwitterionic) or negatively charged SUVs. Taking into account of this behavior, CPPs may be separated into two groups, interconnecting different CPP families. $\mathrm{kFGF}$ and $\mathrm{Nle}^{54}$-Antp show an high affinity towards DMPC SUVs, meanwhile Tat and oligoarginines show an high affinity towards mixed DMPC/DMPG (3:1 molar ratio) SUVs, and this behavior is strongly related to the number $(\mathrm{R} 6<\mathrm{R} 8<\mathrm{R} 10)$ of arginine residues.

Table 2. Surface partition coefficients $\left(\mathrm{K}_{\mathrm{p}}\right)$ of the investigated peptides in SUVs of different composition. The standard errors are less than 5\% (n.d.: not determined).

\begin{tabular}{ccccc}
\hline Peptide & pI & DMPC & DMPG & DMPC/DMPG \\
\hline $\mathbf{1}$ & 5.57 & $1.9 \times 10^{7}$ & $8.6 \times 10^{6}$ & $1.7 \times 10^{6}$ \\
$\mathbf{1 a}$ & 2.11 & $5.2 \times 10^{4}$ & n.d. & $1.0 \times 10^{4}$ \\
$\mathbf{2}$ & 12.31 & $4.1 \times 10^{8}$ & $4.5 \times 10^{7}$ & $6.0 \times 10^{7}$ \\
$\mathbf{2 a}$ & 7.06 & $1.2 \times 10^{5}$ & $4.4 \times 10^{5}$ & $3.3 \times 10^{5}$ \\
$\mathbf{3}$ & 12.70 & $6.9 \times 10^{7}$ & $1.1 \times 10^{8}$ & $5.4 \times 10^{8}$ \\
$\mathbf{3 a}$ & 8.83 & $6.0 \times 10^{3}$ & $1.5 \times 10^{4}$ & $2.0 \times 10^{3}$ \\
$\mathbf{4}$ & 12.70 & $3.2 \times 10^{7}$ & $3.2 \times 10^{8}$ & $1.7 \times 10^{9}$ \\
$\mathbf{4 a}$ & 5.63 & $2.5 \times 10^{4}$ & $5.7 \times 10^{4}$ & $2.9 \times 10^{4}$ \\
$\mathbf{5}$ & 12.85 & $6.6 \times 10^{7}$ & $1.7 \times 10^{8}$ & $3.3 \times 10^{9}$ \\
$\mathbf{5 a}$ & 9.55 & $5.5 \times 10^{6}$ & $1.1 \times 10^{8}$ & $1.1 \times 10^{6}$ \\
$\mathbf{6}$ & 12.95 & $3.5 \times 10^{8}$ & $2.2 \times 10^{8}$ & $4.5 \times 10^{9}$ \\
$\mathbf{6 a}$ & 11.10 & $3.3 \times 10^{8}$ & $1.5 \times 10^{9}$ & $3.8 \times 10^{9}$ \\
\hline
\end{tabular}

The relationship between $\mathrm{K}_{\mathrm{p}}$ constants and peptide composition can be expressed taking into account of the peptide $\mathrm{p} I$ values (Table 2). Apparently, peptides 2-6, characterized by very similar $\mathrm{p} I$ 
values, show a linear deviation of $\mathrm{K}_{\mathrm{p}}$ values in presence of negatively charged DMPG or DMPC/DMPG SUVs. Interestingly, the $K_{p}$ values of Nle ${ }^{54}$-Antp $\left(K_{p} D M P C>K_{p}\right.$ mixed $\left.>K_{p} D M P G\right)$, as well as the comparison of the $\mathrm{K}_{\mathrm{p}}$ values of Tat and R6, having the same $\mathrm{p} I$ (12.70), show the influence of hydrophobic residues in addition to the positively charged ones in the binding process.

These results fit with the data reported by Liu and Deber [17], and may be summarized as follows: hydrophobic peptides, i.e. kFGF, bind and insert into lipid vesicles predominantly via hydrophobic interaction between the lipid fatty acid acyl chains and the hydrophobic peptide segment, showing high affinity towards DMPC vesicles. On the other hand, the insertion into phospholipid vesicles of peptides with low hydrophobic character may be viewed as a two step process, in which the primary electrostatic attraction (between the anionic lipid heads and the cationic side-chains of basic residues) is essential for the binding process, driving the peptides to the membrane surface. Subsequently, the hydrophobic interaction with the lipid acyl chains stabilizes the peptide-membrane interaction and affects peptide insertion.

The analysis of the binding isotherms by means of which the $K_{p}$ were determined, provides useful information on the organization of the peptide within the membrane. Isotherm shapes are almost straight lines, suggesting a simple partition process. They differ from those observed for several poreforming polypeptides, for which initially the curves are flat, but then their slopes rise sharply (about 100 fold) once a threshold concentration is achieved [18].

The conjugation with HS1pY strongly altered both conformational and binding properties of the tested CPPs. The remarkable $\mathrm{K}_{\mathrm{p}}$ differences between vector and HS1pY conjugated peptides are mainly related to the electrostatic repulsion among the negative charges of HS1pY side-chains and the surface charges of phospholipid vesicles, confirming the important role played by electrostatic forces in the interaction of peptides with phospholipid membranes. In particular kFGF-HS1pY did not interact with DMPG vesicles, and the $\mathrm{K}_{\mathrm{p}}$ determined in the presence of mixed SUVs is about one half of that of the parent peptide $\mathbf{1}$. This behavior is shared by the other CPPs (see Table 2 and Figure 3), in particular is noteworthy the low affinity of the Tat peptide 2a. On the other hand, the positive effect on lipid affinity of the high number of arginine residues is also highlighted by the $K_{p}$ of the R10 derivative (6a): only for this peptide the $K_{p}$ values of free and conjugated form are comparable.

\subsection{Membrane Permeability Induced by Peptides}

The efficiency of cell-penetrating peptides and corresponding HS1pY conjugates to perturb the lipid packing and causing leakage of vesicular contents has been examined. Increasing amount of selected peptide was added to mixed DMPC/DMPG vesicles containing the fluorescent dye calcein. An increase in fluorescence intensity due to the relief from the self-quenching of the calcein molecule concentrated $(70 \mathrm{mM})$ within SUVs indicates the dye release.

The relation between the apparent percent of leakage and the peptide-to-lipid molar ratio was reported in Figure 4 and indicated that none of the CPPs induces a significant leakage of dye from vesicles. In the same way even at very high peptide/lipid molar ratio $(>1)$, the corresponding conjugates cannot significantly permeabilize vesicles as indicated by a low percentage of leakage $(<20 \%)$. 
Figure 4. Membrane permeabilization induced by peptides. The level of membrane permeabilization was estimated by the percent of leakage of calcein from mixed DMPC/DMPG SUVs, in Tris-HCl buffer $20 \mathrm{mM}, \mathrm{NaCl} 150 \mathrm{mM}$, and EDTA $1 \mathrm{mM}$, pH 7.4 , at $25^{\circ} \mathrm{C}$.
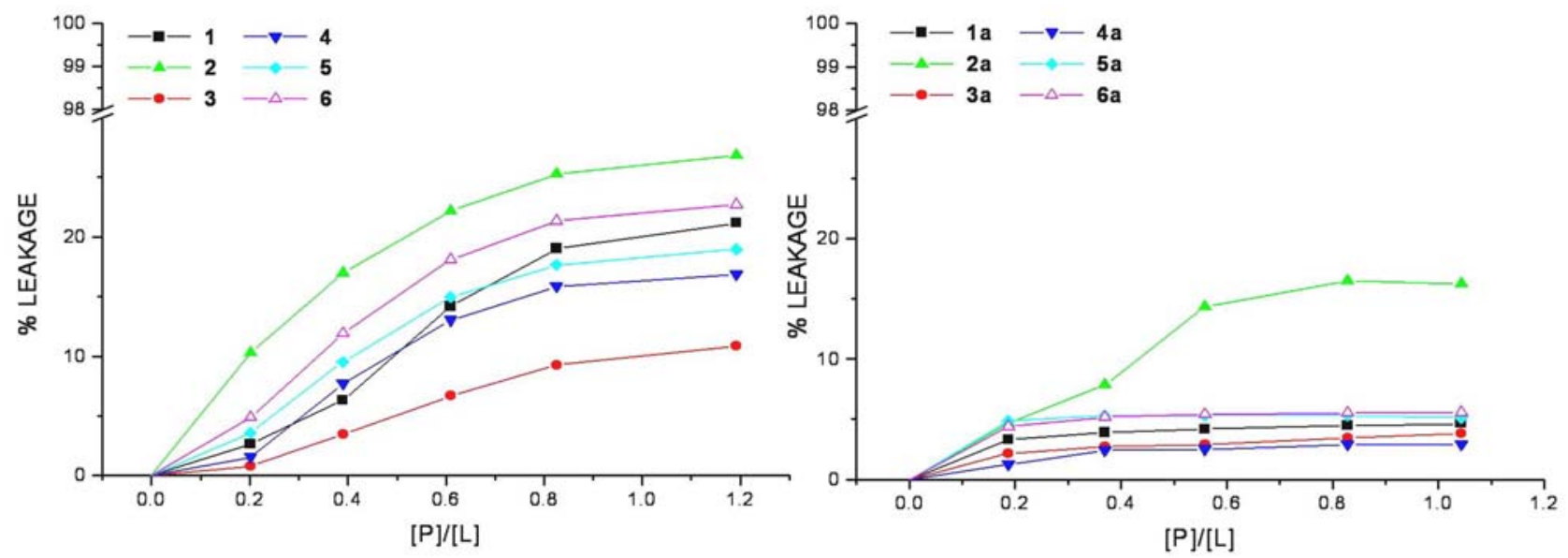

Peptide-induced leakage of calcein entrapped in vesicles can be used to monitor membrane perturbation related to peptide toxicity. As shown in Figure 4, all the selected CPPs are nontoxic even at extremely elevated peptide-to-lipid ratios causing no or little calcein leakage. This property remains unaltered in the corresponding conjugated peptides, rather they show a low lytic capability in comparison to parent peptides, this may be related to the decrease of lipid affinity.

These data furnish useful information on the peptide-lipid interactions in the context of the interaction models that currently exist. In agreement with the low-lytic properties of peptides in vesicle systems and with the data obtained from the binding isotherms, it is possible to assert that the tested peptides do not form pores in the manner of certain antimicrobial peptides. Consequently, our data do not support the "carpet" and the "barrel-stave" mechanism models both inducing pore-formation $[18,19]$.

\subsection{Monitoring the Secondary Structure of Peptides by Circular Dichroism.}

The conformational state of cell-penetrating peptides and their HS1pY conjugates in membrane mimicking environments and bound to phospholipid vesicles has been studied by CD spectroscopy.

In aqueous buffer solution the CD spectra of free CPPs were characterized by the absence of a dominating secondary structure at room temperature. On the other hand, at low temperature Tat and oligoarginine (peptides 3 - 6) exhibited a CD pattern that closely resembles that of an extended lefthanded polyproline II ( $\left.\mathrm{PP}_{\mathrm{II}}\right)$ helix conformation [20,21].

As shown in Figure 5, the CD spectrum of Tat at low temperature $\left(10^{\circ} \mathrm{C}\right)$ is characterized by a strong negative band at $196 \mathrm{~nm}$ and a weak positive band at about $223 \mathrm{~nm}$. On raising the temperature, the $223 \mathrm{~nm}$ positive band disappears, meanwhile the absolute value of negative band at $196 \mathrm{~nm}$ decreases. In addition, an isodichroic point at 210-215 nm was observed permitting to describe this system as a combination of two different states, where the low-temperature form was best described by a $\mathrm{PP}_{\mathrm{II}}$ like conformation. 
Figure 5. Far-UV CD spectra of Tat peptide (13.5 mM) in Tris-HCl buffer (5mM, pH 6.8) as a function of increasing temperature.

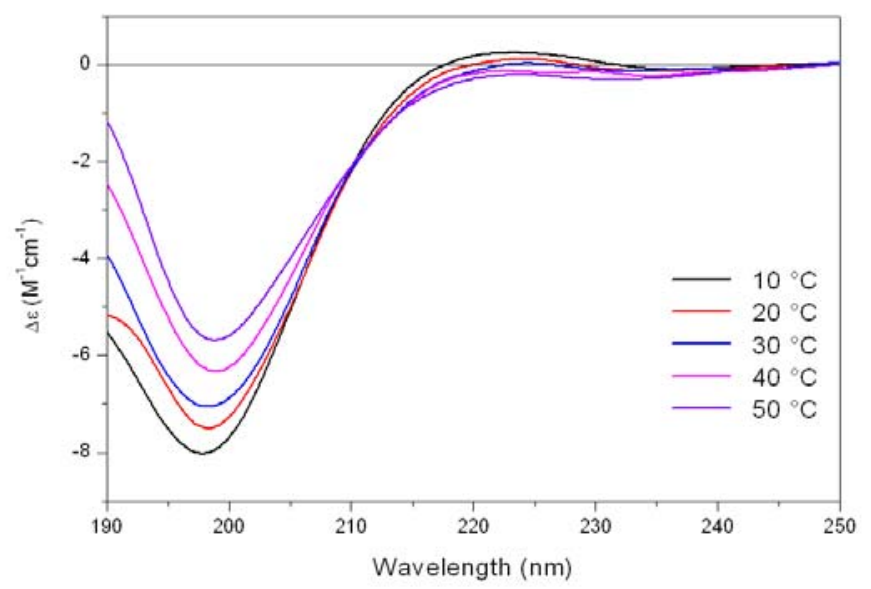

The propensity of charged peptides to adopt an extended left-handed $3_{1}$-helix was initially proposed by Krimm and Mark [22] who demonstrated as electrostatic interactions would favor a helical rather than an unordered structure in ionized polypeptides. In these cases, when the steric energy is taken into consideration, the favored conformation is a left-handed helix having 2.5 - 3.0 residues per turn, where residues at positions $i$ and $i+3$ lie on the same edge of the helix. These results were confirmed by CD studies on ionized poly $(\mathrm{Glu})_{\mathrm{n}}$ or poly(Lys) $)_{\mathrm{n}}$ by Holzwarth and Doty [23] which showed that the spectra of these compounds differ significantly from those characteristic of unordered polypeptides, while resembling that of the $\mathrm{PP}_{\mathrm{II}}$ helix. In this way, the uncharged residues of Tat are located on the same edge of the helix, whereas the Arg and Lys residues are mostly located on the other two sides of the $\mathrm{PP}_{\mathrm{II}}$ helix, and the adopted spatial disposition is suitable for the interaction with the cellular membrane representing the first step of the internalization process.

Ho et al. [24], using LINUS protein structure and GRASP molecular surface predictive programs, suggested that this peptide might have similarities with the amphipatic $\alpha$-helix structure present in many plasma membrane fusing peptides, like toxins, and designed a potent cell penetrating peptide (33-fold increase in translocation) derived from Tat, containing only three arginine residues at the 4, 7 and 10 positions. In contrast with this finding, other groups reported lack of $\alpha$-helicity for Tat as detected by CD measurements [11,25], confirming our results.

In SDS micelles and in 9:1 v/v TFE/buffer, the CD spectra of $\mathrm{kFGF}$ and $\mathrm{Nle}^{54}$-Antp peptides (peptides 1 and 2) were characterized by two negative bands at 222 and $208 \mathrm{~nm}$, respectively, and a positive maximum at $193 \mathrm{~nm}$, characteristic of the presence of $\alpha$-helical structures. Also the Tat peptide (peptide 3) adopted an $\alpha$-helix conformation in 90\% TFE solution, meanwhile in micellar SDS solution its behavior closely resembles that showed in aqueous solution: a left-handed $\mathrm{PP}_{\mathrm{II}}$ like conformation at low temperature and an unordered conformation at room temperature (20). On the contrary, the CD spectra of oligoarginine peptides in both 90\% TFE and in micellar SDS solution were characterized by a negative band at about $200 \mathrm{~nm}$ at all tested temperatures, characteristic of the irregular conformation of the peptide chain. 
In the presence of phospholipid SUVs, CPPs exhibited a conformational behavior completely different from that showed in membrane mimicking environment (SDS micelles or TFE). In particular, the $\mathrm{Nle}^{54}$-Antp peptide (peptide 2) showed a largely random conformation in presence of zwitterionic DMPC vesicles, whereas in presence of anionic DMPG SUVs the peptide adopted mainly a $\beta$-sheet structure. In mixed DMPC/DMPG vesicles the CD spectrum strongly resembled that of an $\alpha$-helix where the negative band is centered at $222 \mathrm{~nm}$ (data not shown). On the contrary, the kFGF peptide (peptide 1) adopted mainly an $\alpha$-helix conformation in all tested phospholipids (Figure 6A). The amount of $\alpha$-helix conformation was not significantly affected by the change of temperature below and above lipid gel to liquid crystal phase transition (about $23{ }^{\circ} \mathrm{C}$, data not shown). The estimated helicities were $35-40 \%$ in the presence of either DMPG or DMPC/DMPG vesicles and 55-60\% in the presence of DMPC SUVs, respectively.

In the presence of zwitterionic or mixed vesicles the CD spectra of the Tat peptide were similar to those observed both in buffer and in micellar SDS solutions at room temperature. On the contrary, the CD pattern in presence of negatively charged DMPG vesicles closely resembled that obtained in $90 \%$ TFE solution, even if the negative band at $222 \mathrm{~nm}$ disappeared in a shoulder (data not shown).

The CD spectra of oligoarginines in presence of DMPC and mixed DMPC/DMPG SUVs were characterized by an evident positive band near $220 \mathrm{~nm}$ and a negative band at about $200 \mathrm{~nm}$, which intensity decreased at the increasing of the percentage of negatively charged phospholipid.

Figure 6. Far-UV CD spectra of kFGF (1) $(11.9 \mu \mathrm{M})(\mathrm{A})$ and of kFGF-HS1pY (1a) (10.9 $\mu \mathrm{M})(\mathrm{B})$ in presence of SUVs of different composition (Mixed, DMPC, DMPG).
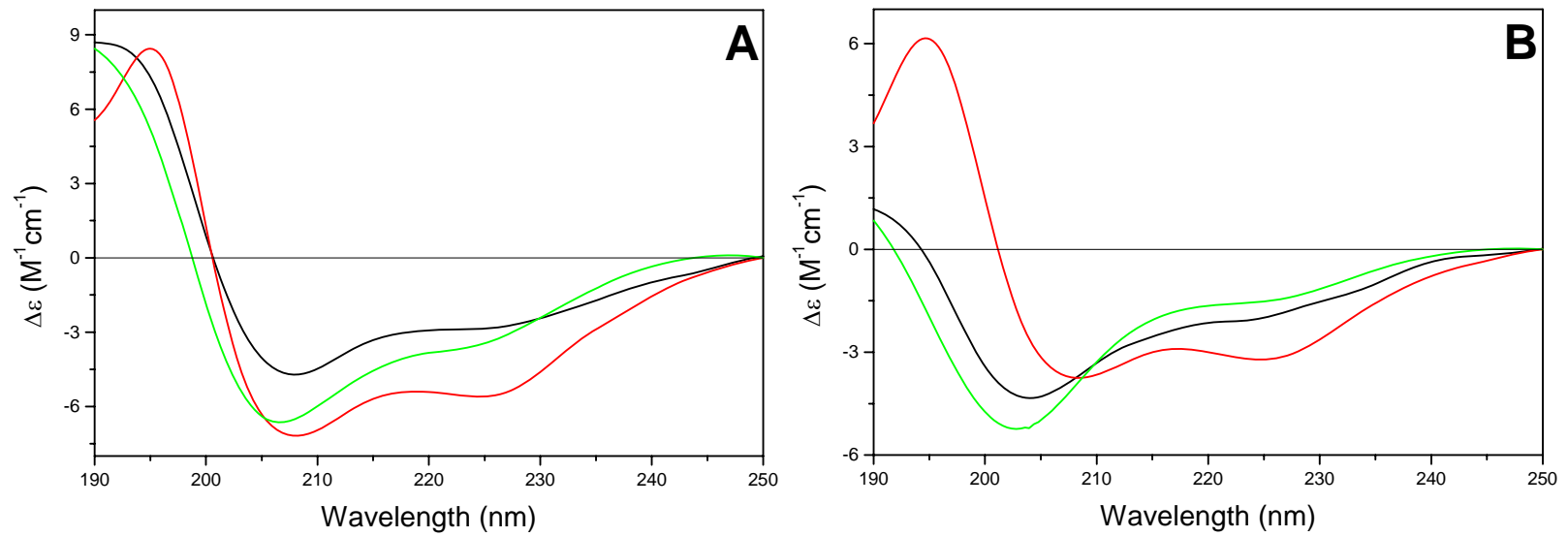

The conjugation with HS1pY peptide strongly affected the CD spectra of all CPPs, even if a rationalization of its effect is not possible. The characteristic $\alpha$-helical conformation of the kFGF peptide (peptide 1) decreased or disappeared. In particular, in the presence of negatively charged SUVs, the CD spectrum of peptide 1a was characterized by a negative band at 202-203 nm with a shoulder at about $225 \mathrm{~nm}$. The intensity of the negative band was strongly correlated to the charge density of SUV: it was maximum in the presence of DMPG vesicles and decreased with increasing the amount of DMPC phospholipids in the SUVs (Figure 6B).

A very similar behavior was observed for the Antp containing peptide 2a. The elongation with HS1pY decreased the helical contribute both in micellar SDS and in 90\% TFE solutions. In presence of zwitterionic DMPC vesicles the conjugated peptide adopts a largely irregular conformation, whereas 
the CD spectra in presence of DMPG or mixed vesicles closely resemble those described for the corresponding kFGF derivative.

The conjugation of HS1pY with Tat (peptide 3a) stabilized the $\mathrm{PP}_{\mathrm{II}}$ like conformation in buffer and in DMPC vesicles. On the contrary, the propensity to adopt an ordered structure in presence of negatively charged SUVs (DMPG or mixed vesicles) as well as in membrane mimicking environments (SDS and TFE) was strongly reduced, and the CD spectra are characterized by the presence of a negative band at about $200 \mathrm{~nm}$.

The introduction of the HS1pY peptide to the C-terminal end of oligoarginine peptides (peptides 4a - 6a) induced very similar changes in the CD spectra recorded under different conditions. In buffer solution the CD spectra were characterized by the presence of two positive band at about 200 and 225 $\mathrm{nm}$, meanwhile in micellar SDS solution the spectra showed a strong negative band at about $200 \mathrm{~nm}$, with a shoulder at $225-230 \mathrm{~nm}$. A very similar behavior was observable in the CD spectra in the presence of phospholipid vesicles. In particular, in the presence of DMPC or DMPG phospholipids the spectra were characterized by a positive band at $230 \mathrm{~nm}$, suggesting the presence of a $\mathrm{PP}_{\mathrm{II}}$ helix conformation. Surprisingly, the CD spectra of peptides $\mathbf{4 a}, 5 \mathbf{a}$ and $\mathbf{6 a}$ in TFE solution were characterized by a very low intensity of the dichroic signal and by the presence of negative band at 205 $\mathrm{nm}$ and positive band at about $190 \mathrm{~nm}$.

\subsection{Delivery of HS1pY peptide into mammalian cells}

The cell peptide uptake was examined by confocal microscopy (Figure 7), using the carboxyfluoresceinyl labeled peptides. Briefly, the peptides were added $(12.5 \mu \mathrm{M})$ to the incubation medium of $\mathrm{CHO}$ (Chinese hamster ovary) cells, for $30 \mathrm{~min}, 1 \mathrm{~h}$ and $2 \mathrm{~h}$ at $37^{\circ} \mathrm{C}$. Cells were washed and peptide internalization detected by confocal microscopy. In these conditions, previous detected membrane-induced carboxyfluorescein quenching (see fluorescence studies) did not affect in efficient way the cell peptide uptake detection.

Surprisingly, the conjugation of the HS1pY peptide destroyed the cell-penetrating properties of kFGF and R6 constructs (peptides 1a and 4a), meanwhile all the other constructs (peptides 2a, 3a, 5a and 6a) were internalized by cells. Maximal internalization was reached after $30 \mathrm{~min}$; prolonged incubation times did not increase fluorescence visible inside cells (data not shown). Fluorescence was apparent throughout the cytoplasm and the nuclei of the cells and appeared to localize mainly to the nucleus. Works are in progress to identify the organelle(s) that is accessed with conjugated peptides.

Figure 7 also shows that, while the parent phospho-decapeptide (peptide 7) could not penetrate cells at $4{ }^{\circ} \mathrm{C}$ (panel A), few fluorescence spots were visible inside control cells incubated at $37^{\circ} \mathrm{C}$, probably as a consequence of an endocytotic process (panel C).

The comparison of these data with the data of our biophysical investigation suggested that the single interaction with the cell membrane and its binding affinity, evaluated by fluorescence studies on vesicle models, per se do not confer specific translocation features, and more important, do not govern cell-penetrating capability.

Recent works $[26,27]$ showed that the major route for Tat and $\mathrm{Nl}^{54}$-Antp peptide-mediated cellular uptake of cargo is endocytosis, rather than a translocation mechanism. In addition, reevaluation of the mechanism of internalization of cationic CPPs demonstrated that uptake was temperature-dependent 
indicative of a step requiring energy [27] as well as reported for signal peptide vectors (kFGF) $[5,6]$. Cationic peptides that initially accumulated on the cell surface in small patches (a process that was temperature-independent) were then internalized in intracellular vesicular structures. One can hypothesize that the high positive charges of conjugated peptides promote the binding to the cell surface. In addition, CPPs uptake by endocytosis rather than translocation mechanism may explain our difficulty to demonstrate the ability of these cationic peptides to pass across a non-cellular phospholipid bilayer (data not shown).

Figure 7. Confocal analysis of the HS1pY uptake. $\mathrm{CHO}$ cells were incubated at $4{ }^{\circ} \mathrm{C}$ (A) or $37{ }^{\circ} \mathrm{C}$ (B, C and D) for $30 \mathrm{~min}$ with $12.5 \mu \mathrm{M}$ concentration of either the phosphodecapeptide (A and C) or the conjugated Tat (peptide 3a) (B) and kFGF (peptide 1a) (D). Preparation of the cells and details of the microscopy are described in the Experimental Section.

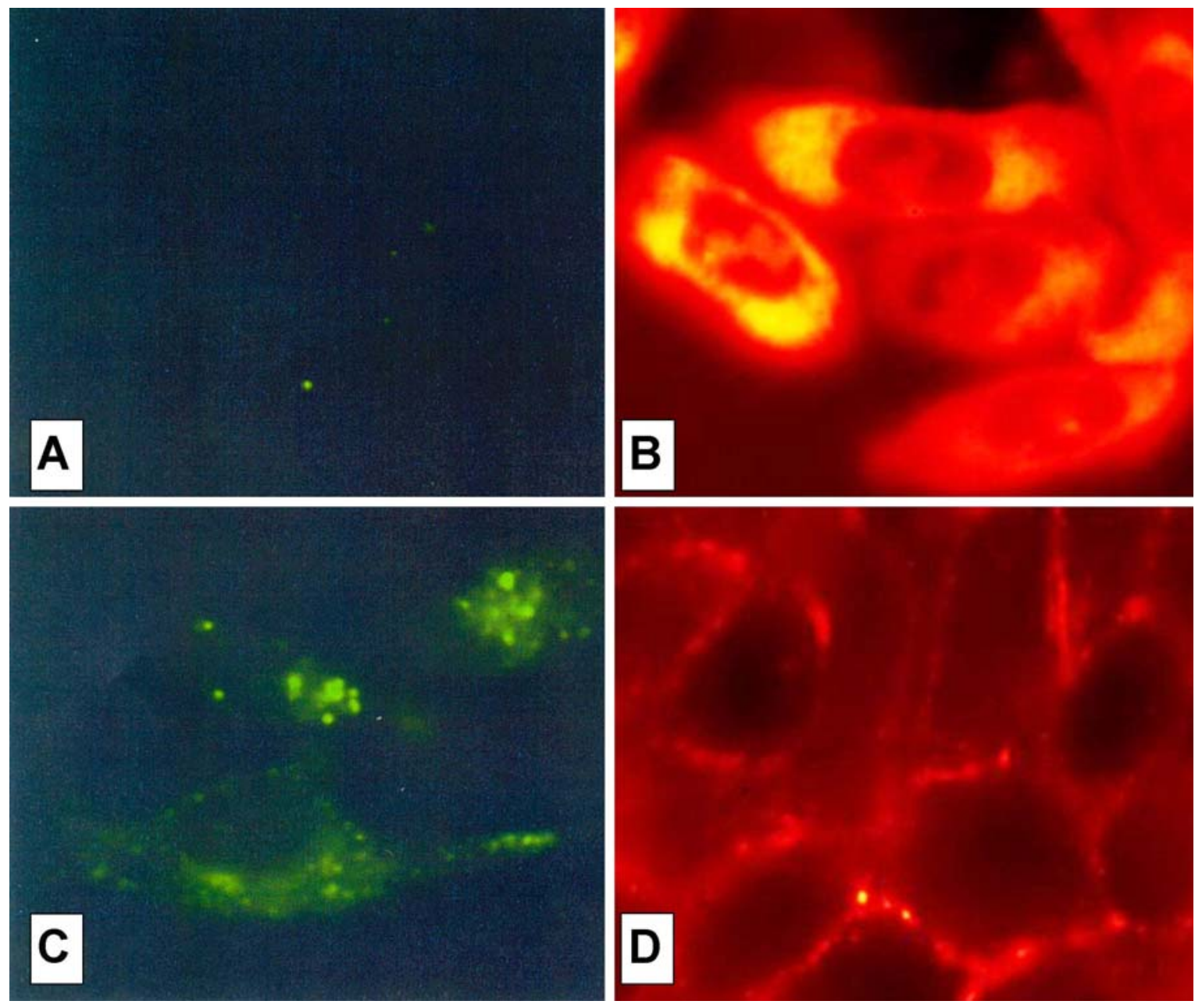

\section{Experimental Section}

\subsection{Peptide Synthesis}

Fmoc-protected amino acids and pre-loaded resins were purchased from Calbiochem-Novabiochem (Läufelfingen, Switzerland). Peptides were synthesized by solid-phase procedures on Wang resin using 
an Advanced Chemtech model $348 \Omega$ peptide synthesizer and the Fmoc chemistry in 0.05 mmolar scale. HBTU/HOBt activation employed a three-fold molar excess $(0.2 \mathrm{mmol})$ of Fmoc-amino acids in DMF solution for each coupling cycle unless otherwise stated. Coupling time was $40 \mathrm{~min}$. Deprotection was performed with $20 \%$ piperidine. Coupling yields were monitored on aliquots of peptide-resin either by the Kaiser test for the amino groups or by evaluation of Fmoc displacement [28]. To preclude side-reactions in the synthesis of the kFGF peptide a pre-loaded H-Pro-2Cl-Trytil resin was used instead of Wang resin [29].

Carboxyfluoresceinyl-labeled peptides were obtained by treatment of $0.025 \mathrm{mmol}$ of H-peptidesresin with $0.1 \mathrm{mmol}$ of (5)6-carboxyfluorescein $N$-succinimide ester (Fluka, Buchs, Switzerland) in presence of $0.2 \mathrm{mmol}$ of DIEA in dry DMF, after elongation of peptide chains with a $\beta$-Ala residue.

Peptides were side-chain deprotected and removed from the resin by TFA treatment in the presence of $2.5 \%$ TIS, $2.0 \%$ anisole and $0.5 \%$ water, and then precipitated by addition of diethyl ether. Crude peptides were purified by preparative reversed-phase HPLC using a Shimadzu LC-8 (Shimazdu,

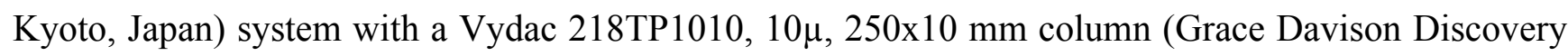
Sciences, Deerfield, IL). The column was perfused at a flow rate of $12 \mathrm{~mL} / \mathrm{min}$ with a mobile phase containing solvent A $(0.05 \%$ TFA in water) and a linear gradient from $10 \%$ to $30 \%$ of solvent $\mathrm{B}$ $(0.05 \%$ TFA in acetonitrile/water, $9: 1$ by vol.) in $40 \mathrm{~min}$. The fractions containing the desired product were collected and lyophilized to constant weight in the presence of $0.01 \mathrm{~N} \mathrm{HCl}$. Analytical HPLC analyses were performed on a Shimadzu LC-10 instrument fitted with a Jupiter C18, $10 \mu$, $250 \times 4.6 \mathrm{~mm}$ column (Phenomenex, Torrance, CA) using the described solvent system (solvents A and B), with a flow rate of $1 \mathrm{~mL} / \mathrm{min}$, and detection at $216 \mathrm{~nm}$. All peptides showed less than $1 \%$ impurities. Molecular weights of compounds were determined by ESI-MS on a Mariner (PerSeptive Biosystem, Foster City, CA) mass spectrometer instrument. The mass was assigned using a mixture of neurotensin, angiotensin and bradykinin, at a concentration of $1 \mathrm{pmol} / \mu \mathrm{L}$, as external standard. The amino acid compositions of the peptide acid hydrolysates $\left(6 \mathrm{M} \mathrm{HCl}, 22 \mathrm{~h}\right.$ at $110{ }^{\circ} \mathrm{C}$ in sealed evacuated vials) were determined with a Carlo Erba 3A30 (Milan, Italy) amino acid analyzer.

\subsection{Vesicles Preparation.}

SUVs were prepared as follows. Phospholipid ( $30 \mathrm{mg}$, about $43 \mu \mathrm{mol}$ ) was dissolved in tert-butanol and lyophilized for two days in a glass tube. The dried lipid was hydrated in $3 \mathrm{ml}$ of $5 \mathrm{mM}$ Tris- $\mathrm{HCl}$ buffer (pH 6.8) with repeated vortexed mixing at $40{ }^{\circ} \mathrm{C}$ for $30 \mathrm{~min}$. The suspension was sonicated for $30 \mathrm{~min}$ (pulse mode: $2.5 \mathrm{sec}$ pulse on, $1.0 \mathrm{sec}$ pulse off) using a microprobe type sonicator (Vibra-Cell, Sonics \& Materials, Inc., Newtown, CT, USA), stabilized for $90 \mathrm{~min}$ at $40{ }^{\circ} \mathrm{C}$ and then centrifuged $(27,000 \mathrm{~g})$. Vesicle sizes were determined by dynamic light scattering using a Nicomp 370 autocorrelator equipped with a Spectra-Physics 2016 argon laser. The average hydrodynamic diameters were of $56 \mathrm{~nm}$ and $36 \mathrm{~nm}$ for DMPG and DMPC vesicles, respectively. These SUVs were used for the CD and fluorescence studies.

Dye-entrapped SUVs were prepared with a lipid film of desired composition by using $70 \mathrm{mM}$ calcein in Tris- $\mathrm{HCl}$ buffer (Tris $20 \mathrm{mM}, \mathrm{NaCl} 150 \mathrm{mM}$, and EDTA $1 \mathrm{mM}$; pH 7.4) as a hydrating solution. Calcein-entrapped vesicles were separated from free calcein on a Sephadex G75 column 
(20 x $1.3 \mathrm{~cm})$. Phospholipid concentration in dye-entrapped SUVs was determined as reported by Raheja et al. [30].

\subsection{Circular Dichroism.}

CD spectra were recorded using a nitrogen-flushed Jasco spectropolarimeter model J715 (Tokyo, Japan) using a $0.1 \mathrm{~cm}$ quartz cell. The CD spectra were recorded using a bandwidth of $2 \mathrm{~nm}$, a scan speed of $10 \mathrm{~nm} / \mathrm{min}$ and a time constant of $4 \mathrm{~s}$. All spectra were recorded in the $5 \mathrm{mM}$ Tris-HCl, $\mathrm{pH}$ 6.8 buffer. Each spectrum was the average of six scans with background of the buffer subtracted. Temperature was controlled at $25^{\circ} \mathrm{C}$ by a Haake model $\mathrm{F} 3$ temperature controller. The helical content was determined using the CDPro software analysis program [31]. This program uses three methods for estimating protein secondary structure fractions from CD spectra. These methods are implemented in the software packages CONTIN/LL, SELCON3, and CDSSTR. Each of these three methods uses a different algorithm for analyzing a given protein $C D$ spectrum, but they all use a single data-file structure [31].

\subsection{Fluorescence spectroscopy.}

Fluorescence emission spectra were recorded on a Perkin-Elmer fluorescence spectrophotometer LS-50B (Norwalk, CT) using emission and excitation slit widths of $5 \mathrm{~nm}$ at $25{ }^{\circ} \mathrm{C}$ under constant magnetic stirring, subtracting the buffer background and correcting for dilution. Excitation wavelengths were at $485 \mathrm{~nm}$ for carboxyfluoresceinyl moiety and the emission spectra were recorded from 500 to $640 \mathrm{~nm}$. Absorbance for all solutions at the excitation and emission wavelengths was less than 0.05 units to minimize inner-filter effects.

Spectroscopic titrations of peptides with SUVs were performed as reported by Surewicz and Epand [32]. Appropriate aliquots of DMPC, DMPG or DMPC-DMPG (3:1 molar ratio) liposomes were successively added to a solution $(2.5 \mathrm{ml})$ of peptides in Tris- $\mathrm{HCl}$ buffer $(5 \mathrm{mM}$, pH 6.8). After each addition of liposomes, the mixture was kept at $25{ }^{\circ} \mathrm{C}$ for $5 \mathrm{~min}$ to achieve the equilibrium. The binding isotherms were analyzed as a partition equilibrium using the following formula:

$$
\mathrm{X}_{\mathrm{b}}=\mathrm{K}_{\mathrm{p}} \mathrm{C}_{\mathrm{f}}
$$

where $X_{b}$ is defined as the molar ratio of bound peptide per total lipid, $K_{p}$ corresponds to the partition coefficients, and $\mathrm{C}_{\mathrm{f}}$ represents the equilibrium concentrations of the free peptide in the solution. The curve resulting from plotting $X_{b}$ versus the free peptide concentration, $C_{f}$, is referred to the conventional isotherm. To calculate $X_{b}$, the fraction of the membrane bound peptide $f_{b}$ is determined with the following formula:

$$
\mathrm{f}_{\mathrm{b}}=\left(\mathrm{F}-\mathrm{F}_{0}\right) /\left(\mathrm{F}_{\infty}-\mathrm{F}_{0}\right)
$$

where $F_{0}$ is the fluorescence of the unbound peptide, $F$ the fluorescence of the bound peptide, and $F_{\infty}$ the fluorescence signal obtained when all the peptide is bound to lipids. In several cases, the plateau level reached during titration was taken as $\mathrm{F}_{\infty}$, but in those instances where no plateau was achieved, a value for $\mathrm{F}_{\infty}$ was extrapolated from a double reciprocal plot of $\mathrm{F}$ (total peptide fluorescence) versus $\mathrm{C}_{\mathrm{L}}$ (total concentration of lipids), as previously suggested by Schwarz [33]. With $\mathrm{f}_{\mathrm{b}}$ known, the $\mathrm{C}_{\mathrm{f}}$ value as well as the extent of peptide binding $\left(\mathrm{X}_{\mathrm{b}}\right)$ could be calculated. Partition coefficients were calculated from the initial slope of each conventional isotherm (for details of the calculation, see [33, 34]). 
The release of calcein from SUVs was monitored by fluorescence at an emission wavelength of 520 $\mathrm{nm}$ (excitation wavelength of $490 \mathrm{~nm}$ ). The maximum fluorescence intensity corresponding to $100 \%$ leakage was determined by addition of $10 \mu \mathrm{L}$ of $10 \%$ Triton X-100 to the sample $(3 \mathrm{ml})$. The apparent percent leakage was determined according the following equation:

$$
\%=100 \bullet\left(\left(\mathrm{F}-\mathrm{F}_{0}\right) /\left(\mathrm{F}_{\max }-\mathrm{F}_{0}\right)\right)
$$

where $\mathrm{F}$ and $\mathrm{F}_{\max }$ correspond to the fluorescence intensity before and after the addition of detergent, respectively. $F_{0}$ represent the fluorescence of intact vesicles. Peptide concentrations were determined either by absorption spectroscopy $\left(\varepsilon_{485 \mathrm{~nm}}=80,000 \mathrm{~cm}^{-1} \mathrm{M}^{-1}\right)$ or by the average amino acid recovery from acid hydrolyzate of an aliquot of the peptide solutions.

\section{5. pI determination}

The $\mathrm{p} I$ values were calculated using the Demo version of Protein Tools ${ }^{\mathrm{TM}}$ (ChemSW, Fairfield, CA, USA). The $\mathrm{pK}_{\mathrm{a}}$ values for the acidic amino acid residues were: 4.0 for Asp, 4.4 for Glu, 10.0 for Tyr and 3.5 for the $\mathrm{C}$-terminal carboxylate. For the basic residues, $\mathrm{pK}_{\mathrm{a}}$ values used were: 12.0 for $\mathrm{Arg}, 10.0$ for Lys and 8.0 for the $\mathrm{N}$-terminal amine. For the phosphate group attached to tyrosine, $\mathrm{pK}_{\mathrm{a} 1}$ of 1.0 and $\mathrm{pK}_{\mathrm{a} 2}$ of 6.1 were used [35].

\subsection{Cell Penetration Assay.}

CHO cells were seeded into glass coverslips at 30,000 cells/well in Ham's F12 medium with 10\% fetal calf serum and antibiotics. After overnight incubation, phospho-peptides were prepared as dilution series in cell medium $(12.5,25$ and $50 \mu \mathrm{M})$ and were added to cells. At the end of the incubation ( $30 \mathrm{~min}, 1 \mathrm{~h}$ and $4 \mathrm{~h}$ ) at both $4{ }^{\circ} \mathrm{C}$ and $37^{\circ} \mathrm{C}$, cells were rinsed with PBS three times and fixed for $30 \mathrm{~min}$ at $4{ }^{\circ} \mathrm{C}$ in formaldehyde (4\% in PBS), rinsed again and treated with $50 \mathrm{mM} \mathrm{NH}_{4} \mathrm{Cl}$. Coverslips were then mounted in glycerol for observation of cells by fluorescence microscopy. Fluorescence microscopy was carried out using a Zeissew Axiovert 100, equipped with a 12 bit digital CCD videocamera Micromax (Princeton Instruments, Trenton, NJ, USA). Data were acquired and analyzed by Metamorph software (Universal Imaging).

\section{Conclusions}

The potential application of CPP-mediated transport in vivo necessitates knowledge about the mechanism of transport and the influence of cargoes on the cellular uptake of particular CPPs. CD and fluorescence spectroscopies furnished useful information about the secondary structure of both free and conjugated CPPs in membrane-mimicking environments and their interaction with phospholipid vesicles, respectively, yielding useful enlightenment on the initial steps of CPP-mediated cellular uptake, which has been postulated to be the interaction of CPP with lipids in the plasma membrane. As shown in Figure 3, with the exception of R10 derivative, CPPs and their HS1pY conjugates are characterized by an evidently different affinity towards phospholipids that may be explained invoking the electrostatic repulsion between negatively charged SUV and HS1pY cargo. In a previous work, Jiang et al. [36] used an anionic peptide (six to nine consecutive Glu residues) to block the cellular uptake of a polycationic CPP ( 9 Arg residues) by intramolecular electrostatic interaction. To realize 
this inhibition the authors introduced between the CPP and the polyanionic peptide a cleavable sequence that can adopt a turn conformation. The absence in our conjugates of a suitable sequence minimizes or does not permit the realization of these intramolecular interactions. On the contrary, intermolecular interactions, as demonstrated by Jiang et al. [36], are indifferent in the inhibition of the cellular uptake, and so also in modify the affinity of CPP-conjugates towards SUVs. Cellular uptake experiments showed that not all tested CPP-HS1pY constructs have been internalized inside cells, even if interacted with phospholipids vesicles.

Therefore, even if certain physico-chemical properties (conformation, positive charge, hydrophobicity, and amphipathicity) may govern the initial step of the cellular uptake of these peptides, our data suggest that there is not any correlation with the uptake properties of the peptides in the cell line tested, indicating that other properties, in addition to lipid binding, might be involved in the initial binding to the membrane and subsequent translocation process of CPPs.

\section{Acknowledgements}

This work was supported by grants from the National Research Council (CNR) of Italy.

\section{References and Notes}

1. Maiolo, J.R.; Ferrer, M.; Ottinger, E.A. Effects of cargo molecules on the cellular uptake of arginine-rich cell-penetrating peptides. Biochim. Biophys. Acta Biomembr. 2005,1712, 161-172.

2. Stewart, K.M.; Horton, K.L.; Kelley, S.O. Cell-penetrating peptides as delivery vehicles for biology and medicine. Org. Biomol. Chem. 2008, 6, 2242-2255.

3. Langel, Ü., Ed. Handbook of Cell-Penetrating Peptides; CRC Press: Boca Raton, FL, USA, 2007.

4. Komi, A.; Suzuki; M.; Imamura, T. Permeable FGF-1 Nuclear Localization Signal Peptide Stimulates DNA Synthesis in Various Cell Types but Is Cell-Density Sensitive and Unable to Support Cell Proliferation. Exp.Cell. Res. 1998, 243, 408-414.

5. Lin, Y.Z.; Yao, S.Y.; Hawiger, J. Role of the Nuclear Localization Sequence in Fibroblast Growth Factor-1-stimulated Mitogenic Pathways. J. Biol. Chem. 1996, 271, 5305-5308.

6. Lin, Y.Z. ; Yao, S.Y.; Veach, R.A.; Torgerson, T.R.; Hawiger, J. Inhibition of nuclear translocation of transcription factor NF- $\kappa$ B by a synthetic peptide containing a cell membranepermeable motif and nuclear localization sequence. J. Biol. Chem. 1995, 270, 14255-14258.

7. Prochiantz, A. Messenger proteins: homeoproteins, TAT and others. Curr. Opin. Cell Biol. 2000, 12, 400-406.

8. Sebbage, V. Cell-penetrating peptides and their therapeutic application. Bioscience Horizons 2009, 1, 64-72.

9. Derossi, D.; Joliot, A.H.; Chassaing, G.; Prochiantz, A. The third helix of the Antennapedia homeodomain translocates through biological membranes. J. Biol. Chem. 1994, 269, 10444-10450.

10. Ruzza, P.; Donella Deana, A.; Calderan, A.; Brunati, A.M.; Massimino, M.L.; Elardo, S.; Mattiazzo, A.; Pinna, L.A.; Borin, G. Antennapedia/HS1 chimeric phosphotyrosyl peptide: conformational properties, binding capability to c-Fgr SH2 domain and cell permeability. Biopolymers 2001, 60, 290-306. 
11. Futaki, S.; Suzuki, T.; Ohashi, W.; Yagami, T.; Tanaka, S.; Ueda, K.; Sugiura, Y. Arginine-rich peptides. J. Biol. Chem. 2001, 276, 5836-5840.

12. Rothbard, J.B.; Kreider, E.; Pattabiraman, K.; Pelkey, E.T.; VanDeusen, C.L.; Wright, L.; Wylie, B.L.; Wender, P.A. Cell-Penetrating Peptides: Processes and Applications; Langel, Ü., Ed.; CRC Press , Boca Raton,FL, USA, 2002; pp. 141-160.

13. Saalik, P.; Elmquist, A.; Hansen, M.; Padari, K.; Saar, K.; Viht, K.; Langel, U.; Pooga, M. Protein Cargo Delivery Properties of Cell-Penetrating Peptides. A comparative study. Bioconjugate Chem. 2004, 15, 1246-1253.

14. Fischer, R.; Fotin-Mleczek, M.; Hufnagel, H.; Brock, R. Break on through to the other side Biophysics and cell biology shed light on cell-penetrating peptides. ChemBioChem 2005, 6, 21262142.

15. Ruzza, P.; Donella Deana, A.; Calderan, A.; Biondi, B.; Brunati, A.M.; Favretto, D.; Pinna, L.A.; Borin, G. Peptides 1998; Bajusz, S., Hudecz, F., Eds.; Akadémiai Kiadó: Budapest, Hungary, 1999; pp. 628-629.

16. Ruzza, P.; Elardo, S.; Calderan, A.; Donella-Deana, A.; Crisma, M.; Brunati, A.M.; Massimino, M.L.; Pinna, L.A.; Borin, G. In Peptides 2002; Benedetti, E., Pedone, C., Eds.; Edizioni Ziino: Naples, Italy, 2002, pp. 876-877.

17. Liu, L.P.; Deber, C.M. Anionic Phospholipids Modulate Peptide Insertion into Membranes. Biochemistry 1997, 36, 5476-5482.

18. Shai, Y. Mechanism of the binding, insertion and destabilization of phospholipid bilayer membranes by $\alpha$-helical antimicrobial and cell non-selective membrane-lytic peptides. Biochim. Biophys. Acta 1999, 1462, 55-70.

19. Zasloff, M. Antimicrobial peptides of multicellular organisms. Nature 2000, 415, 389-395.

20. Ruzza, P.; Calderan, A.; Guiotto, A.; Osler, A.; Borin, G. Tat cell-penetrating peptide has the characteristic of a poly(proline) II helix in aqueous solution and in SDS micelles. J. Pept. Sci. 2004, 10, 423-426.

21. Lam, S.L.; Hsu, V.L. NMR identification of left-handed polyproline type II helices. Biopolymers 2003, 69, $270-281$.

22. Krimm, S; Mark, J.E. Conformations of polypeptides with ionized side chains of equal length. Proc. Natl. Acad. Sci. USA 1968, 60, 1122-1129.

23. Holzwarth, G.; Doty, P. The ultraviolet circular dichroism of polypeptides. J. Am. Chem. Soc. 1965, 87, 218-228.

24. Ho, A.; Schwarze, S.R.; Mermelstein, S.J.; Waksman, G.; Dowdy, S.F. Synthetic protein transduction domains: enhanced transduction potential in vitro and in vivo. Cancer Res. 2001, 61, 474-477.

25. Vives, E.; Brodin, P.; Lebleu, B. A truncated HIV-1 Tat protein basic domain rapidly translocates through the plasma membrane and accumulates in the cell nucleus. J. Biol. Chem. 1997, 272, 16010-16017.

26. Richard, J.P.; Melikov, K.; Vives, E.; Ramos, C.; Verbeure, B.; Gait, M.J.; Chernomordik, L.V.; Lebleu, B. Cell-penetrating Peptides. A reevaluation of the mechanism of cellular uptake. J. Biol. Chem. 2003, 278, 585-590. 
27. Console, S.; Marty, C.; Garcia-Echeverria, C.; Schwendener, R.; Ballmer-Hofer, K. Antennapedia and HIV transactivator of transcription (TAT) "Protein Transduction Domains" promote endocytosis of high molecular weight cargo upon binding to cell surface glycosaminoglycans. $J$. Biol. Chem. 2003, 278, 35109-35114.

28. Wellings, D.A.; Atherton, E. Standard Fmoc protocols. In Solid-Phase Peptide Synthesis; Fields, G. B., Ed; Academic Press, NY, USA,1997; Vol. 289, pp 44-67.

29. Steinauer, R.; White, P. Innovations and Perspectives in Solid Phase Synthesis - 3rd International Symposium; Epton, R., Ed.; Mayflower Worldwide Ltd.: Birmingham, UK, 1994; pp. 689-692.

30. Raheja, R.K.; Kaur, C.; Singh, A.; Bhatia, I.S. New colorimetric method for the quantitative estimation of phospholipids without acid digestion. J. Lipid Res. 1973, 14, 695-697.

31. Sreerama, N.; Woody, R.W. Estimation of protein secondary structure from circular dichroism spectra: comparison of CONTIN, SELCON, and CDSSTR methods with an expanded reference set. Anal. Biochem. 2000, 287, 252-260.

32. Surewicz, W.K.; Epand, R.M. Role of peptide structure in lipid-peptide interactions: a fluorescence study of the binding of pentagastrin-related pentapeptides to phospholipid vesicles. Biochemistry 1984, 23, 6072-6077.

33. Schwarz, G.; Gerke, H.; Rizzo, V.; Stankowski, S. Incorporation kinetics in a membrane, studied with the pore-forming peptide alamethicin. Biophys. J. 1987, 52, 685-692.

34. Drin, G.; Mazel, M.; Clair, P.; Mathieu, D.; Kaczorek, M.; Temsamani, J. Physico-chemical requirements for cellular uptake of pAntp peptide - Role of lipid-binding affinity. Eur. J. Biochem. 2001, 268, 1304-1314.

35. Kyte, J. Structure in Protein Chemistry, Garland Publishing, New York, NY, USA, 1995.

36. Jiang, T.; Olson, E.S.; Nguyen, Q.T.; Roy, M.; Jennings, P.A.; Tsien, R.Y. Tumor imaging by means of proteolytic activation of cell-penetrating peptides. Proc. Natl. Acad. Sci. USA 2004, 101, 17867-17872.

(C) 2010 by the authors; licensee Molecular Diversity Preservation International, Basel, Switzerland. This article is an open-access article distributed under the terms and conditions of the Creative Commons Attribution license (http://creativecommons.org/licenses/by/3.0/). 